\title{
RECONSTRUINDO UMA IMAGEM: um estudo semiótico comparativo das identidades visuais do PT nas eleições municipais de 2012 e 2016 em São Paulo, Belo Horizonte e Poços de Caldas
}

\author{
Conrado Moreira Mendes ${ }^{1}$ \\ Matheus Henrique Sanaiotte ${ }^{2}$
}

Resumo: O presente artigo apresenta os resultados de pesquisa que objetivou realizar uma análise semiótica comparativa na identidade visual dos candidatos do Partido dos Trabalhadores (PT) à prefeitura de três cidades brasileiras: São Paulo (SP), Belo Horizonte (MG) e Poços de Caldas (MG), respectivamente Fernando Haddad (2012 e 2016); Patrus Ananias (2012) e Reginaldo Lopes (2016); Eloísio Lourenço (2012 e 2016). Partindo da hipótese de que o cenário conturbado da política brasileira e, principalmente, os escândalos envolvendo o PT motivaram uma tentativa de desvinculação dos candidatos ao respectivo partido nas eleições de 2016, como base na semiótica de Peirce e em estudos sobre sintaxe visual, procurou-se demonstrar como se construíram as estratégias semiótico-comunicacionais em cada campanha política no sentido de desvincular a imagem do candidato à do Partido dos Trabalhadores. Com base nas análises, foram identificadas as estratégias semióticocomunicacionais em cada caso. $\mathrm{Na}$ análise comparativa entre as campanhas de Fernando Haddad em $2012 \mathrm{em}$ relação a 2016, identificou-se a estratégia denominada de "humanização"; na campanha de Patrus Ananias em relação à de Reginaldo Lopes, identificou-se a estratégia denominada de "alegria visual", finalmente, no que se refere à campanha de Eloísio Lourenço, identificou-se a estratégia denominada de "metáfora do alvorecer". Cada uma delas tratou de desvincular a candidatura do candidato ao Partido dos Trabalhadores.

Palavras-chave: Campanha Eleitoral; Identidade Visual; Política; Semiótica.

\begin{abstract}
This paper presents the results of a research that aimed to perform a comparative semiotic analysis on the visual identity of Partido dos Trabalhadores' (PT - Workers' Party) candidates to the prefecture of three Brazilian cities: São Paulo (SP), Belo Horizonte (MG) e Poços de Caldas (MG), respectively Fernando Haddad (2012 e 2016); Patrus Ananias (2012) e Reginaldo Lopes (2016); Eloísio Lourenço (2012 e 2016). Starting from the hypothesis that the turbulent scenario of Brazilian politics and, mainly, the scandals involving the PT motivated an attempt to untie the candidates to the respective party in the 2016 elections, as a basis in Peirce's semiotics and in studies on visual syntax, it was tried to demonstrate how the semiotic-communicational strategies were constructed in each political campaign in order to disassociate the image of the candidate from that of the Workers' Party. Based on the analyzes, the semiotic-communicational strategies were identified in each case. In the comparative analysis between the campaigns of Fernando Haddad in 2012 in relation to 2016, the so-called "humanization" strategy was identified; in the campaign of Patrus Ananias in relation to that of Reginaldo Lopes, the so-called "visual joy" strategy was identified. Finally, with regard to the campaign of Eloísio Lourenço, the so-called "metaphor of dawn" strategy was identified. Each of them tried to disassociate the candidate's candidacy from the Workers Party.
\end{abstract}

Keywords: Electoral Campaign; Visual identity; Policy; Semiotics.

\footnotetext{
${ }^{1}$ Doutor em Semiótica e Linguística Geral pela Universidade de São Paulo (2013). Professor Adjunto I da Pontifícia Universidade Católica de Minas Gerais (PUC-MG), Departamento de Comunicação Social e docente do Programa de Pós-graduação em Comunicação Social da PUC Minas. E-mail: conradomendes@yahoo.com.br

2 Estudante de Graduação do Curso de Publicidade e Propaganda na Pontifícia Universidade Católica de Minas Gerais, campus Poços de Caldas. Bolsista de Inicicão Científica (FAPEMIG) do Programa de Bolsas de Iniciação Científica (PROBIC) da PUC-Minas. E-mail: matheussanaiotte@gmail.com
} 


\section{Introdução}

O presente artigo apresenta os resultados da pesquisa que objetivou realizar uma análise semiótica comparativa na identidade visual dos candidatos do Partido dos Trabalhadores (PT) à prefeitura de três cidades brasileiras: São Paulo (SP), Belo Horizonte (MG) e Poços de Caldas (MG). Visou-se, assim, a cotejar as diferenças nas identidades visuais das campanhas dos candidatos do PT considerando os anos de 2012 e 2016 em São Paulo (Fernando Haddad 2012 e 2016); Belo Horizonte (Patrus Ananias 2012 e Reginaldo Lopes 2016) e Poços de Caldas (Eloísio Lourenço 2012 e 2016). A pesquisa parte da hipótese de que o cenário conturbado da política brasileira e, principalmente, os escândalos envolvendo o PT motivaram uma tentativa de desvinculação dos candidatos ao respectivo partido nas eleições de 2016. Assim, como base na semiótica de Peirce e em estudos sobre sintaxe visual, procurou-se demonstrar como se construíram as estratégias semióticocomunicacionais em cada campanha política no sentido de desvincular a imagem do candidato à do Partido dos Trabalhadores.

O que motiva essa tentativa de desvinculação entre a imagem dos candidatos das referidas prefeituras em relação ao PT são as diversas denúncias de corrupção envolvendo o partido, desde 2005, com as primeiras denúncias do escândalo político do Mensalão, e se intensificaram em 2016, com o impeachment de Dilma Rousseff, e as constantes denúncias e prisões efetuadas na Operação Lava-jato, que acontecem até os dias atuais. Assim, parte-se do pressuposto de que o cenário político brasileiro está em crise, e as constantes notícias produzidas pela mídia influenciaram as estratégias comunicacionais das campanhas eleitorais municipais dos candidatos no ano de $2016^{3}$.

Pelo contexto político, pode-se inferir que o cenário eleitoral em 2016 era desfavorável aos candidatos da legenda do PT. Tudo isso contribuiu para a construção de uma imagem negativa do partido e a ligação desse aos escândalos de corrupção. Com isso, os candidatos do PT às prefeituras em 2016, tinham um grande obstáculo para suas candidaturas,

\footnotetext{
${ }^{3}$ Em virtude dos limites deste trabalho, não será o caso de retomar o contexto político brasileiro que antecedeu as eleições municipais de 2016. Para isso, remetemos aos trabalhos de Almeida (2017), Guazina; Prior; Araújo (2017) e Rizotto; Prudencio; Sampaio (2017).
} 
ser um candidato do PT sem ter a vinculação de sua imagem aos escândalos políticos, e ao próprio partido, que estava passando por uma crise profunda de identidade.

\section{Roteiro de análise}

A análise acontece por meio dos conceitos da teoria semiótica de Peirce (SANTAELLA, 1983, 2002) e sobre sintaxe visual (DONDIS, 2007). Entende-se semiótica como "ciência que tem como base as categorias fenomenológicas, estuda os signos, códigos, as linguagens, ou seja, qualquer forma de se comunicar, de significar, de produzir sentido" (SANTAELLA 1983, p. 8-12). Esta pesquisa utilizará o ramo da gramática especulativa da semiótica peirciana, que engloba a teoria geral de classificação e definição dos signos.

A análise aqui empreendida segue um roteiro didático construído por Santaella (2002), no qual se faz primeiramente a análise do fundamento do signo (significação) e de sua relação com o objeto (referência) dentro de três pontos de vista: ponto de vista qualitativo-Icônico; ponto de vista singular-indicial; ponto de vista convencional-simbólico. Finalmente, é analisado a relação do signo com o interpretante, considerando os tipos de efeitos que o signo está apto para produzir, enquanto interpretante emocional, energético e lógico.

O referido roteiro de análise tem como primeira etapa a contemplação do signo: contemplamos os signos, devemos nos abrir aos fenômenos. Depois disso, passamos para uma análise do signo e seu fundamento, o que faz com que o signo represente algo, seja uma qualidade, o seu caráter existencial singular, ou uma força de lei. O próximo passo é analisar a relação do signo com o objeto, analisando o objeto dinâmico que é o objeto que o signo irá sugerir/associar, indicar/referir-se ou representar/substituir. O modo como o signo irá se referir ao objeto é o objeto imediato, é o recorte da realidade, de seu objeto que o signo faz, o signo se refere ao seu objeto de modo icônico, indicial ou simbólico, de acordo com seu fundamento. A última análise é a da relação do signo com o efeito interpretativo que ele produz em um intérprete, analisando os níveis dos interpretantes, o imediato e o dinâmico. O interpretante imediato é um efeito interpretativo em potencial, que está interno no signo, ainda em nível abstrato. É algo que ele está apto a produzir como efeito interpretativo. O interpretante dinâmico é a efetivação do interpretante, tem se aí o caráter psicológico singular 
do intérprete. Este possui três níveis de efeito interpretativo que são de acordo com a primeiridade a secundidade e a terceiridade.

- Emocional: nesse nível o signo produz como interpretante qualidades de sentimento, sensações, não apenas sentimentos como alegria e tristeza, mas impressões sobre o signo, que muitas vezes são indecifráveis ou vagas.

- Energético: o signo produz como interpretante uma reação no intérprete, seja ela física ou mental.

- Lógico: o signo é interpretado por regras, conhecimentos internalizados pelo intérprete. Esse interpretante está em constante transformação com as mudanças de hábitos entre outras coisas as regras internalizadas e novas regras se transformam.

\section{Apresentação do corpus da pesquisa}

A seguir, apresenta-se o corpus da pesquisa, composto pelas identidades visuais dos candidatos à prefeitura municipal das cidades de São Paulo, Belo Horizonte e Poços de Caldas em 2012 e em 2016.

São Paulo, 2012: Fernando Haddad

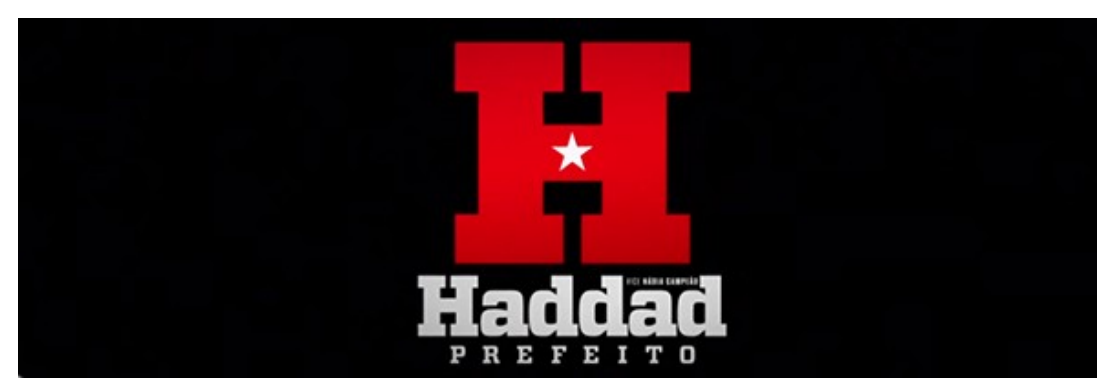

São Paulo, 2016: Fernando Haddad

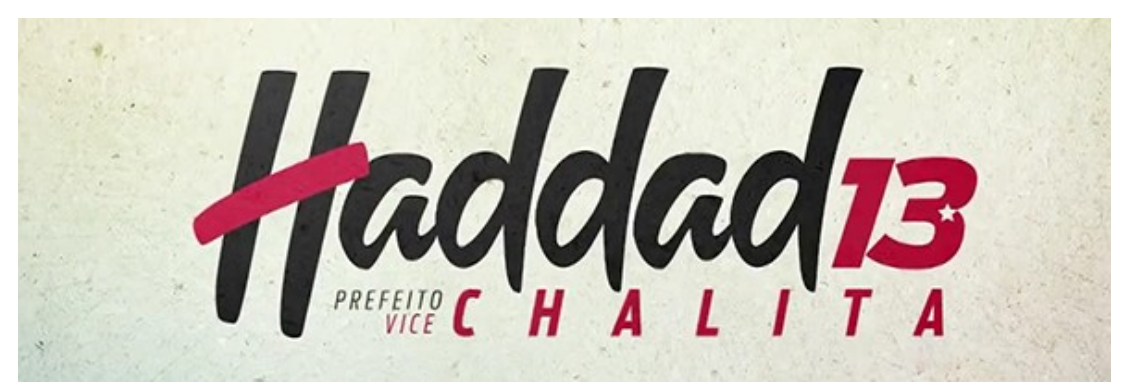


Belo Horizonte, 2012: Patrus Ananias

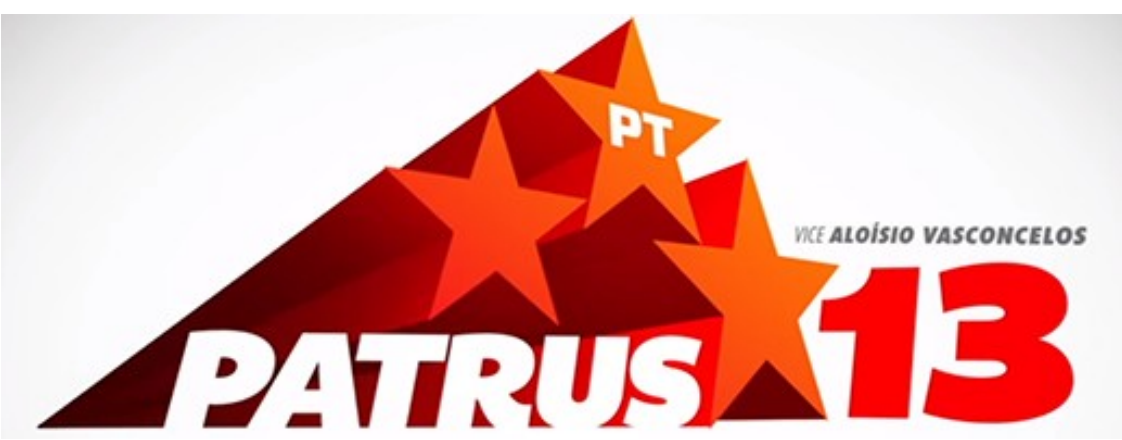

Belo Horizonte, 2016: Reginaldo Lopes

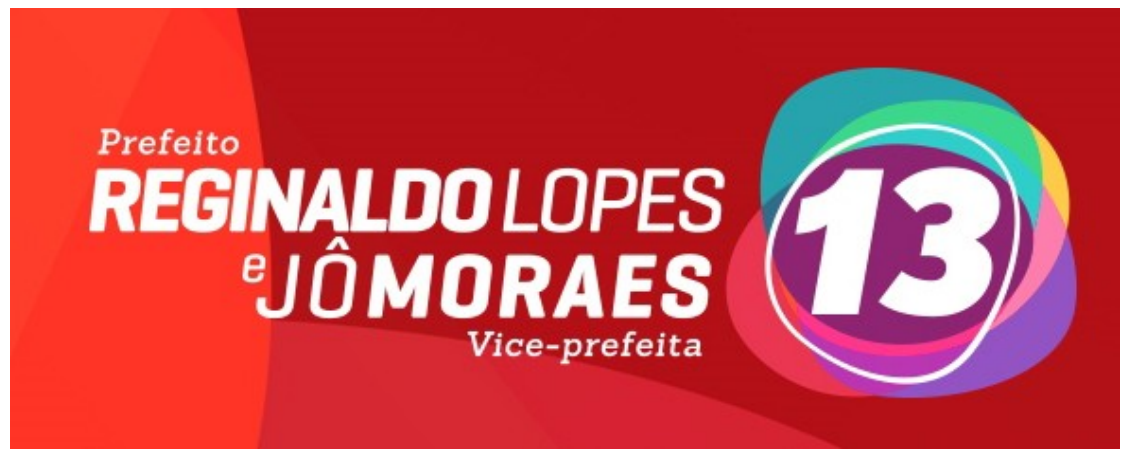

Poços de Caldas, 2012: Eloísio Lourenço

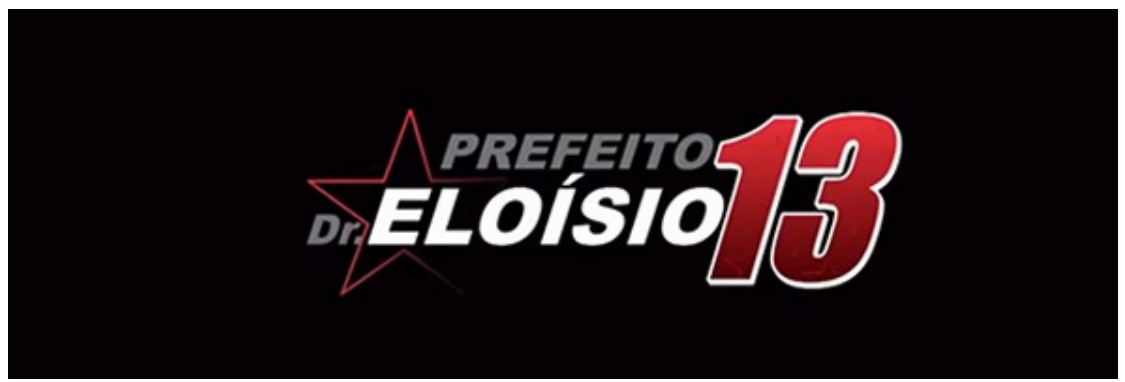

Poços de Caldas, 2012: Eloísio Lourenço

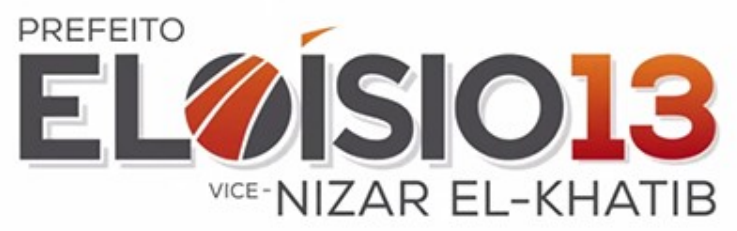

4. Análise semiótica das identidades visuais das campanhas políticas

// REVISTA DISPOSITIVA, v. 6, n. 10 // 
Primeiramente serão descritos os pontos em comum entre todas as identidades visuais, para evitar algumas repetições na análise.

$\mathrm{Na}$ maioria das campanhas, temos a presença dos nomes dos candidatos a prefeito, e dos candidatos a vice-prefeito (com exceção da campanha de Eloísio em 2012, que não possui o nome de seu vice). Os nomes são índices das pessoas, são signos existentes, que indicam seus objetos, que são os candidatos, pessoas, que são outros existentes.

Outro ponto em comum nas campanhas é a presença da palavra prefeito (com exceção de Patrus Ananias em 2012) e vice-prefeito, que são palavras que simbolizam os cargos públicos de maior autoridade em um munícipio, e indicam o cargo pretendido pelos candidatos. A partir desses signos, é possível entender que tais identidades visuais se tratam de uma campanha para eleições municipais, mas nenhuma delas possui índices sobre qual cidade os candidatos estão tentando se eleger.

Temos também a presença do número 13 nas campanhas, que, dentro do contexto político brasileiro, simboliza o PT, suas ideologias, suas ações, seus candidatos e tudo que está vinculado ao partido. E mesmo que os candidatos busquem se desvincular da imagem do PT, não podem deixar de utilizar em suas campanhas o número 13, pois ele os identifica, é o número em que os eleitores utilizam para votar naquele candidato. O número tem, assim, força de lei.

Em algumas dessas campanhas, há a presença da cor vermelha e também a forma de uma estrela (logotipo/símbolo do PT), esses elementos possuem força de lei, maior que seu valor qualitativo. A cor vermelha dentro do contexto político é símbolo da ideologia socialista, do comunismo e, no Brasil, ela está presente na identidade visual de partidos de esquerda, partidos que tem como ideologia fazer políticas sociais, como o PPS, PCdoB, e, evidentemente, o PT. Nos objetos em análise, a cor é utilizada nas campanhas para vincular à essa ideologia social, e ao PT. A estrela na política também é um símbolo do PT dentro do contexto político brasileiro, e muitas vezes se apresenta juntamente a sigla do partido (PT).

Mas o essencial da identidade visual de uma campanha eleitoral é seu aspecto singular. A identidade visual de uma campanha é criada com elementos que identifiquem o candidato, suas propostas, suas atitudes, e diferencie uma campanha das outras. Cada elemento é utilizado de modo que se diferencie de outras campanhas, e consiga criar a identidade do 
candidato. Tal identidade é uma abstração, que busca englobar todos os aspectos que envolvem o candidato e expressá-los visualmente. Nenhuma campanha pode ser semelhante no aspecto visual, para não causar confusão no eleitor e em qualquer um que busque identificar um candidato.

\section{Análise das identidades visuais do candidato do PT às eleições municipais de} São Paulo em 2012 e 2016

\subsection{Análise da identidade visual da campanha de Haddad 2012}

No que diz respeito ao ponto de vista qualitativo-icônico, na identidade visual da campanha de 2012 de Fernando Haddad, temos três cores: branca, vermelha e preta. A cor vermelha possui uma leve variação de tom, com tons mais escuros nas extremidades da forma que ela preenche, a forma da letra " $\mathrm{H}$ ", e um vermelho mais claro, mais saturado ao centro, essa variação da cor vermelha, e escala da letra " $H$ " dos signos, traz a sensação de vigor, de poder, de imponência.

Devido ao grande tamanho que a letra $\mathrm{H}$ possui em uma relação de escala entre os elementos, ela ganha destaque, se torna visualmente o principal elemento da composição, como se fosse a marca, o logotipo do candidato. E ao entendermos como logotipo o $\mathrm{H}$, ele se associa a logotipos de heróis de quadrinhos, como Capitão América, Lanterna Verde, Super Homem, devido as linhas bem definidas, as cores, a estrela no centro e a imponência desse elemento, a própria palavra herói inicia com a letra $\mathrm{H}$.

Com a cor preta de fundo, a cor vermelha ganha destaque assim como a branca. "Fundos escuros dão destaque para as cores que se sobrepõem a ele, fundos claros amenizam as cores sobrepostas, a utilização de um fundo escuro pode ter como objetivo destacar a importância de outras cores, outros elementos" (PEREZ, 2004, p.78). Essa combinação de cores produz impacto visual muito grande. E essa sensação impactante, é reforçada pela forma da letra $\mathrm{H}$ que se assemelha a forma de um tanque de combate visto de cima.

A tipografia utilizada se enquadra na classe de serifa grossa segundo Williams (2013, p. 156), essa classe surgiu com a revolução industrial e a publicidade, suas linhas retas transmitem a sensação de solidez e força, todos os seus traços são grossos e com linhas perfeitamente retas e as serifas são horizontais, essas características fazem com que a 
tipografia não pareça ter sido produzida manualmente, e sim de modo mecânico, de modo industrial.

Quanto ao ponto de vista singular-indicativo, a ausência do número 13 na identidade, número que identifica o candidato, indica que o partido é facilmente identificado, e o número de sua legenda está implícito nos outros signos, como o seu nome, e os signos que identificam seu partido. A estrela dentro do $\mathrm{H}$ cumpre a função de indicar o partido a que pertence o candidato.

Sobre o ponto de vista convencional simbólico, temos um potencial símbolo, que é a letra $\mathrm{H}$ que é utilizada como logotipo do candidato, uma marcam do candidato. Ela também carrega a cor vermelha que é símbolo do socialismo e essa representação é reforçada pela estrela branca, ambos os signos são símbolos do socialismo e do PT.

No nível interpretativo, no tocante ao interpretante imediato, os signos da identidade de Haddad tem como potencial causar impacto visual, devido ao contraste das cores vermelha e branca com o fundo preto, e a utilização de uma tipografia de serifa grossa. Também é possível vincular a identidade de Haddad ao seu partido, o PT, devido a presença dos símbolos de modo evidente, no centro da composição.

Acerca do interpretante dinâmico, em nível emocional, as sensações produzidas acontecem devido as qualidades da identidade visual, sem considerar o aspecto de ser uma identidade de campanha política, os signos trazem a sensação de impacto devido à imponência das cores e formas que são muito impactantes.

No nível energético, de ação ou reação como interpretante, os signos da identidade visual fazem com que a identifiquemos como uma campanha política, devido ao cargo desejado. Outra ação é buscar identificar o número do candidato, no qual está ausente na identidade, e também buscar enxergar o nome da vice de Haddad, Nádia Campeão, devido ao tamanho pequeno, quase ilegível em relação a escala que ela se encontra na composição.

No nível lógico, primeiro pensamento ao se ver os signos é o de vinculação com uma campanha política do PT, devido ao modo de destaque que seus símbolos (a estrela e a cor vermelha) se apresentam, no centro da composição.

Ao se ter conhecimento sobre a ideologia social do partido é possível identificar também símbolos e elementos que se associam ao socialismo, como a estrela, a cor vermelha, que junto ao fundo preto se cria a sensação de algo conflitante, sensação essa que se reforça 
ao associarmos a semelhança da letra $\mathrm{H}$ com a imagem aérea de um tanque de guerra, que reflete muito a história dessa ideologia de luta de classes, lutas para chegar ao poder, lutas realizadas por trabalhadores. A tipografia utilizada faz com que na letra $\mathrm{H}$, em cima e embaixo da estrela, se forme um espaço que se assemelha ao martelo da bandeira comunista, esse martelo representa os trabalhadores industriais e sua força de trabalho.

A letra $\mathrm{H}$ da identidade é utilizada como logotipo da campanha, muitas vezes aparece sozinha, sem a inscrição verbal "Haddad" e, como qualquer logotipo, tem como potencial ser um símbolo a partir de convenções sociais, e conhecimento coletivo. E, como logotipo, a letra H se assemelha a outros logotipos, logos de heróis da ficção, a própria palavra herói inicia com a letra $\mathrm{H}$. Ao associar o logotipo do candidato ao de heróis, podem-se associar as características heroicas ao candidato.

\subsection{Análise da identidade visual da campanha de Haddad 2016}

Do ponto de vista qualitativo-icônico, a campanha de 2016 de Haddad, possui três cores: a cor preta em um tom um pouco mais claro, um tom de vermelho menos saturado, próximo ao tom vinho, bordô, e a cor branca de fundo, no qual possui uma textura de uma superfície porosa, com riscos e manchas, semelhante a uma parede, como se os elementos da composição tivessem sido escritos sobre uma parede, a textura nos passa a sensação de superfície que pode ser ou não confirmada pelo tato (DONDIS, 2007, p. 70), no caso por ser uma imagem, não. O sobrenome "Haddad" está escrito com uma tipografia manuscrita, que parece ser feita por uma pessoa manuseando um pincel, o que contribui para o sentido de a composição ser pincelada em uma parede ou uma superfície.

Ao contemplarmos as formas, podemos notar que a letra $\mathrm{H}$ do sobrenome do candidato Haddad, se assemelha ao símbolo de diferença (dois traços paralelos e um que cruza entre eles), pode-se observar isso ao girarmos a letra $\mathrm{H} \mathrm{em} 90^{\circ}$.

Do ponto de vista singular-indicativo, na composição, temos o nome do candidato a prefeito e do vice, e os cargos muito próximos, o que poderia atrapalhar a leitura, mas com a utilização da cor é possível diferenciar quem é candidato a que cargo, no caso Haddad a prefeito e Chalita a vice. A tipografia é manuscrita, e o texto se torna o vestígio/índice deixado 
pela tinta do pincel. A estrela, que é símbolo do partido, está presente na composição, mas de modo quase imperceptível, ela está em um tamanho muito pequena sobre o número 13.

Do ponto de vista convencional simbólico, temos representação do partido o número 13, e a estrela do partido, mas a estrela está quase imperceptível na composição, está como um detalhe no número 13. A matiz vermelha saturada, que é símbolo do partido e de sua ideologia, não se apresenta, pois, a cor vermelha está presente em um tom menos saturado, próximo da cor vinho. O que descaracteriza o vermelho que representa o PT. A letra $\mathrm{H}$ se apresenta de modo que seja uma letra, e também o símbolo de diferença, com duas linhas paralelas e uma linha diagonal sobreposta a eles.

No que diz respeito ao nível interpretativo, no que se refere ao Interpretante imediato, os signos da identidade têm como potencial interpretativo associá-la a uma pintura, grafite em uma parede, devido as formas da tipografia, que é uma tipografia manuscrita, e a textura semelhante à de uma parede, como fundo. Devido as formas tipográficas serem semelhantes a ação humana, a leitura acompanha essa forma, de modo de que o olhar acompanha os traços como se os estivessem pincelando em uma parede.

A respeito da vinculação com o partido ela não está explicita, devido a cor vermelha símbolo do PT, não estar presente, o que temos é um tom avermelhado, mas muito próximo de um tom rosa escuro. E a estrela do partido está presente de modo quase imperceptível, no número 13.

No que diz respeito ao interpretante dinâmico, em nível emocional, temos a produção de uma sensação tátil, devido a utilização de textura, como fundo da composição, que se assemelha a uma parede, ou qualquer superfície porosa. E também a sensação de movimento devido à utilização de uma tipografia manuscrita com linhas levemente diagonais, podemos sentir e apreender o movimento de escrita do texto.

Em nível energético, ao ler o texto temos a ação de acompanhar o movimento do pincel, pincelando o texto e não apenas ler o sobrenome Haddad.

Em nível lógico, ao observarmos os signos da identidade visual podemos entender que a estratégia foi de atenuar a vinculação com o partido, devido à utilização da cor vermelha, mas de modo descaracterizado e a diminuição da estrela do partido, utilizando-a quase que de modo imperceptível. 
Com a tipografia manuscrita nessa identidade Haddad, ganha um caráter mais humano em comparação com a campanha de 2012, no qual se utilizava uma tipografia de serifa grossa, que parecia ser feita mecanicamente, e agora a de 2016 parece ser feita por uma pessoa.

O símbolo da diferença utilizado de modo que ele teve dupla função, de ser símbolo e de ser a letra $\mathrm{H}$, pode ser entendido como uma mensagem para os eleitores, que Haddad é um político diferente dos outros, principalmente pelas várias denúncias de corrupção a outros políticos, essa mensagem vem para dizer "Eu não sou corrupto, não sou como eles, eu sou diferente". E também podemos entender que Haddad ao colocar o símbolo da diferença, ele se preocupa com os grupos minoritários: mulheres, negros, LGBTs, etc.

Em 2016 como nos anos anteriores o Brasil vive constantemente com protestos, nos protestos as pessoas fazem cartazes pedindo coisas que elas querem, os cartazes são feitos pincelando as frases com tinta, e a identidade utiliza a mesma ideia de pincelar o nome do candidato com tinta. O que podemos entender é que se as pessoas escrevem nos cartazes o que elas querem, ao escrever o nome de Haddad do mesmo modo, a mensagem é de que do mesmo modo que a população pede coisas ao governo, ela pede a candidatura de Haddad.

\section{Análise das identidades visuais dos candidatos do PT às eleições municipais de Belo Horizonte em 2012 e 2016}

\subsection{Análise da identidade visual da campanha de Patrus Ananias 2012}

Do ponto de vista qualitativo-icônico, a identidade visual de Patrus Ananias tem a presença de duas cores em sua composição, a cor vermelha e a cor branca. A utilização da cor vermelha está nas formas estelares, nas quais há uma variação tonal (luz), e no número 13 temos a cor vermelha pura e muito saturada.

Nas estrelas, a cor vermelha tem sua variação tonal de forma gradual, de modo que preenche a forma, que possui linhas retas e bem definidas. As estrelas parecem deixar um rastro, vestígio por onde percorreram, e essa relação dos tons de vermelho junto com a perspectiva das linhas desse rastro criam a ilusão de volume, de tridimensionalidade da forma. Com a variação do tom escuro no canto inferior esquerdo até um tom mais claro do vermelho, próximo ao tom de laranja, no canto superior direito, cria-se a ideia de que as estrelas estão crescendo, estão em movimento, em uma direção diagonal. 
A presença de linhas retas e rígidas tanto na perspectiva quanto na silhueta da forma, contribuem para produzir a sensação de rigidez e solidez, trazem a ideia de que a as estrelas são um bloco sólido. E a silhueta dessa forma se assemelha muito à silhueta de uma montanha, que possui como característica ser sólida e resistente, e assim se reforça a ideia de solidez. Enxergando como uma montanha, podemos observar que as estrelas estão presentes nela como se fossem entalhadas, e acabam por lapidar a montanha, formando um monumento, algo notável pela sua grandeza e magnitude.

A cor branca presente predominantemente como cor de fundo da composição, equilibra visualmente a composição, na qual se tem uma cor muito forte que é a cor vermelha contrastando com uma cor neutra, a branca, que traz tranquilidade, equilíbrio e um alívio visual.

Do ponto de vista singular-indicativo, dentro do contexto das eleições municipais de Belo Horizonte em 2012, a campanha de Patrus possui seus aspectos singulares, os elementos visuais e as técnicas de comunicação utilizadas, são escolhas de composição visual que buscam identificar a campanha de Patrus, diferenciá-la de outros candidatos, e torna-la única. O modo como os signos são dispostos, e se relacionam, acontecem de modo singular.

Do ponto de vista convencional-simbólico, a campanha de Patrus utiliza a cor vermelha e estrelas, e uma delas com a sigla PT (no caso da composição a estrela que está no meio das três, é o logotipo do partido, pois além de a estrela ser vermelha, possui a sigla PT), são cores e formas, são qualidades, mas essas possuem mais valor simbólico do que qualitativo. Ambas as qualidades são, por convenção e força de lei, símbolos de uma política com ideologia social, e também símbolos do Partido dos Trabalhadores.

No nível interpretativo, no que diz respeito ao interpretante imediato, a identidade visual de uma campanha eleitoral de Patrus Ananias tem como objetivo e potencial interpretativo, identificar a campanha de Patrus à prefeitura de Belo Horizonte, e distingui-la de outras campanhas. Outro potencial que o signo produz é o de vinculação da campanha de Patrus ao seu partido, o PT, devido a utilização de símbolos do partido de modo intenso e muito evidente, no qual a campanha tem como característica identificar o partido ao qual pertence, antes mesmo de identificar o candidato.

O interpretante dinâmico em nível emocional, no caso da campanha de Patrus, temos como interpretante a sensação de magnitude, grandeza, devido a predominância 
compositiva da Forma 1, que na composição possui uma escala maior que os outros elementos, como o próprio nome do candidato. E também essa magnitude é reforçada pela sensação de solidez e rigidez que é produzida devido a utilização de linhas retas e bem definidas, a perspectiva e a variação de tons da cor vermelha, com destaque para a forma das estrelas que estão em um tom quase da cor laranja pois simulam como se essa a Forma 1 estivesse voltada para uma luz amarelada, a luz do sol.

Em nível energético, os signos da campanha de Patrus fazem com que a reação do intérprete seja de identificar e relacionar a campanha ao candidato, ao partido, às eleições de 2012 em Belo Horizonte.

Em nível lógico, o intérprete entenderá que a identidade visual se trata de uma campanha política, se trata de um determinado candidato, de um determinado partido, a partir do momento que ele tem internalizado em si o conhecimento sobre campanhas eleitorais, ter conhecimento sobre o candidato, sobre o partido ao qual é filiado, etc. Assim, ele poderá concluir que aquela identidade visual faz parte de uma campanha política, do candidato Patrus Ananias, que é filiado ao PT, um partido de ideologia de esquerda, de políticas sociais.

\subsection{Análise da identidade visual da campanha de Reginaldo Lopes 2016}

Do ponto de vista qualitativo-icônico, a identidade visual da campanha de Reginaldo Lopes possui uma abundância de cores, linhas e formas. A identidade possui muitas cores, podemos observar a presença da cor vermelha, a cor azul, verde, amarelo, roxo, o que faz com que as informações que estão na cor branca ganhem destaque, em função do contraste. Além disso, devido à utilização de muitas cores, a campanha produz animação, alegria visual, contemplação, bem-estar, sensações essas que pouco se associam a uma campanha política.

As formas possuem linhas curvas, são círculos irregulares, achatados, que contribuem para intensificar a sensação de animação das cores, e agregam a ideia de movimento e de ação, o movimento não é algo visível, mas é algo que está implícito nas formas, e pode ser observado apenas quando já se teve alguma experiência com esse movimento, que no caso é um movimento circular, segundo Dondis (2007, p. 80).

Outro aspecto qualitativo, é a relação visual de igualdade entre o tamanho dos nomes do candidato a prefeito e sua vice, essa relação de igualdade é estabelecida por uma qualidade, 
a escala dos nomes, algo a se destacar já que não se apresenta nas outras campanhas dessa pesquisa.

Do ponto de vista singular-indicativo, os quali-signos citados contribuem para a construção de uma identidade única e diferenciada da campanha de Reginaldo Lopes, pois as campanhas políticas utilizam em maioria, as cores do partido, ou cores semelhantes, mas, nesse caso, temos a utilização de muitos matizes, que pouco se associam ao PT, com exceção da cor vermelha, que nesse caso é utilizada com algumas variações.

Outro aspecto a se destacar é a presença do número 13, índice e símbolo do candidato e do seu partido, aplicado na cor branca, envolvido por uma forma circular roxa, que descaracteriza o número como símbolo do partido, que em sua identidade utiliza a combinação da cor branca e vermelha.

Do ponto de vista convencional-simbólico, temos a presença de símbolos do PT, a cor vermelha, e o número 13, mas esses aparecem descaracterizados. A cor vermelha está presente em diversos tons (semelhantes a cor laranja e a cor rosa), e o 13 está na cor branca, envolvido por uma forma circular roxa.

Em nível Interpretativo, no que se refere ao interpretante Imediato, temos como efeito interpretativo uma hesitação na identificação da identidade, sobre o que ela se trata? O que busca comunicar? Seus quali-signos transmitem jovialidade, diversidade, coisas que não se relacionam aos signos presentes, em geral, em uma campanha política: as campanhas políticas não utilizam tantas cores e formas em suas identidades visuais (talvez isso seja o início de uma mudança, uma tendência), pois estamos alfabetizados visualmente de que campanhas políticas possuem signos que se relacionam com o partido, as cores, formas e símbolos.

Acerca do interpretante dinâmico em nível emocional, a predominância qualitativa da identidade produz muito efeitos interpretativos emocionais, sensações e sentimentos. A animação, o movimento, são sensações produzidas pelas formas arredondadas, junto com as cores. Essa identidade possui um aspecto contemplativo, semelhante à contemplação de uma obra de arte, pois os quali-signos constroem uma composição semelhante a um mosaico.

Em nível energético, em uma primeira impressão, a campanha produz uma confusão indicial, não se sabe muito sobre o que se trata. E até mesmo se ela estiver em um contexto de campanha política (como em um programa eleitoral audiovisual). Algo que contribui para a 
identificação de que a composição se trata de uma identidade visual de campanha política é a da colocação de cargos políticos, no qual temos o Prefeito e Vice-prefeita.

A identificação da campanha do candidato Reginaldo Lopes acontece de modo fácil depois da internalização dos signos, pois ela é única, devido aos elementos que possui. Ela se diferencia e muito de outras campanhas políticas, até mesmo de eleições passadas.

Em nível lógico, um dos interpretantes que podemos ter é o da relação de igual importância que o prefeito e sua vice-prefeita possuem na campanha, interpretante esse que é possível alcançar ao se observar a igual escala em que os nomes de ambos estão. Essa igualdade de uma vice-prefeita mulher com o prefeito que é um homem, podemos entender que é reflexo das discussões sociais do contexto em que a campanha aconteceu, em 2016 tivemos muitas manifestações e discussões sobre o empoderamento feminino, o feminismo, a luta pela igualdade entre homem e mulher.

Outra questão social que pode ser refletida é a diversidade cultural, diversidade social, como o movimento LGBT que possui em sua identidade as cores do arco-íris (vermelho, laranja, amarelo, verde, azul, anil e violeta), cores essas que são semelhantes as cores utilizadas na campanha de Reginaldo Lopes. Pode-se relacionar ao candidato o respeito e a preocupação do candidato com a diversidade social, e a luta pela igualdade de direito entre todos.

A vinculação da campanha ao partido acontece de modo ameno, por meio do número 13, que é símbolo do PT, mas que é algo obrigatório, por força de lei, em uma campanha política. Outra vinculação com o partido que é possível de se ter é por meio da cor vermelha, que se apresenta de modo descaracterizado, presente como cor fundo da composição.

\section{Análise das identidades visuais dos candidatos do PT às eleições municipais de Poços de Caldas em 2012 e 2016}

\subsection{Análise da identidade visual da campanha de Eloísio Lourenço em 2012}

Do ponto de vista qualitativo-icônico, a identidade da campanha de Eloísio em 2012 apresenta cores neutras, a cor preta, branca e a cor cinza que é uma variação tonal da cor preta. Junto com elas, a cor vermelha, que se apresenta também com uma variação tonal, desde um vermelho escuro até um vermelho claro. As linhas e formas que estão presentes na 
identidade são retas e simples. A utilização de linhas retas, bem definidas e poucas cores, apenas cores neutras e a cor vermelha, faz com que a campanha comunique simplicidade, sobriedade e seriedade.

Temos a presença da forma de uma estrela constituída apenas pelo seu contorno em vermelho, temos apenas linhas moldando uma estrela, sem completá-la; essa estrela está incompleta, a forma é completada na mente de quem vê, devido à experiência de já tê-la visto. Formas estelares estão também presentes de modo minimalista, quase transparentes, dentro do número 13, quase imperceptíveis. O texto possui uma leve inclinação, pois as linhas são retas e apresentam direção diagonal, essa qualidade produz a ideia de ação, de movimento. Com a utilização do fundo na cor preta, as informações que possuem a cor branca como qualidade ganham destaque, devido ao contraste do preto com o branco.

Do ponto de vista singular-indicial, a campanha de Eloísio em 2012 possui aspectos singulares como seu nome e alguns elementos como a forma incompleta de uma estrela. Temos a utilização de cores neutras juntamente com a cor vermelha, e formas com traços bem definidos, como acontece na campanha de 2012 de Patrus e de Haddad. Com isso, podemos entender que, no ano de 2012, as campanhas de candidatos do PT utilizaram elementos que vinculassem as campanhas ao partido, mas também que criassem um padrão, uma identidade de campanhas do PT.

Do ponto de vista convencional-simbólico, referente aos símbolos, temos a cor vermelha presente no número 13 e na estrela, os três elementos citados são símbolos do PT, signos que vinculam a campanha ao partido.

A aplicação da estrela na identidade visual acontece de modo discreto, pois a estrela está incompleta, essa estratégia se deve ao fato de que a cidade de Poços de Caldas nunca, até então, ter eleito um candidato a prefeito do PT, o que evidencia o conservadorismo político de seu eleitorado. E de modo simbólico, a aplicação de uma estrela incompleta, apenas tracejada, a torna menos símbolo do PT, do que a estrela completa, preenchida, que é utilizada como logotipo do partido. E, nesse caso especifico, já temos, em 2012, uma tentativa de desvinculação em relação ao partido.

Outro signo que carrega um valor coletivo é o pronome de tratamento "Dr.", esse pronome é utilizado como um signo de distinção social, utilizado para tratarmos, falarmos de pessoas importantes, pessoas de autoridade, pessoas de classes sociais superiores. No caso de 
Eloísio, o pronome é utilizado devido ao fato de ele ser graduado em odontologia. Lembre-se que, no passado, havia a convenção tratar esses profissionais pelo pronome "Dr.", assim como acontece com graduados em medicina, direito, entre outros.

Em nível interpretativo, no que diz respeito ao interpretante imediato, a campanha tem como potencial a vinculação com o partido, mas de modo muito discreto, buscando desvincular-se do partido, buscando transmitir ao intérprete, seriedade, sobriedade e competência.

Quando ao interpretante dinâmico, em nível emocional, a campanha transmite é a sensação de seriedade e sobriedade devido às cores e formas neutras e simples da campanha.

Em nível energético, o aspecto qualitativo das linhas que quase formam uma estrela é algo provocativo, pois faz com que o intérprete tenha a ação de completar mentalmente a forma, ação essa que só é possível para quem já teve contato com a forma simbólica de uma estrela.

O nível lógico é produzido o entendimento, o pensamento pelos signos. Eloísio Lourenço em 2012 participou de sua primeira candidatura a um cargo político em Poços de Caldas, e o eleitorado da cidade não tinha como tradição votar em partidos de esquerda, o que são alguns obstáculos a mais em sua candidatura. Entende-se que uma estratégia utilizada foi a de transmitir que ele era um candidato sério, que possuía conhecimento, que era capaz de ser o prefeito da cidade. Como ele fez isso?

Como já foi dito, a identidade de sua campanha comunica ao intérprete seriedade e sobriedade, o que para o eleitor é muito importante em um político. Outro signo que contribui para a comunicação de ser um homem capaz é a utilização do pronome "Dr.", por ser dentista, que agrega a ele autoridade, conhecimento, importância social.

Outro raciocínio é o de vincular a campanha ao PT, pois se tem a presença de símbolos do partido, mesmo que de uma maneira não tão escancarada, como acontece com a estrela símbolo do partido, que está presente na campanha de maneira simples, apenas com o contorno de sua forma. E dessa maneira temos uma menor representação, simbolização do PT, caso houvesse a estrela completa.

7.2 Análise da identidade visual da campanha de Eloísio Lourenço em 2016 
Do ponto de vista qualitativo-icônico, as cores presentes na identidade da campanha são predominantemente neutras, tem-se a utilização do branco como cor de fundo, e do cinza no texto, que possui linhas retas bem definidas.

Há também a cor laranja que apresenta uma variação tonal e uma transição de cima para baixo, do laranja mais escuro até o laranja mais claro. Essa variação do laranja, com o tom mais claro em cima e o escuro embaixo, se assemelha ao nascer de um sol, o nascer de um novo dia, quando contemplamos o nascer do sol no horizonte podemos observar a presença desses tons de laranja no céu.

$\mathrm{Na}$ primeira letra "O" de Eloísio existem 3 linhas brancas e entre elas os tons de laranja, essas linhas estão limitadas pela forma da letra. As linhas são levemente curvadas e estão direcionadas para a diagonal, pois elas vão do canto inferior esquerdo para o canto superior direito, de modo que vão diminuindo o espaço entre elas, criando o efeito de que em algum momento elas irão se tocar em algum ponto. O acento da primeira letra "I" do nome de Eloísio parece o complemento dessas linhas, e ser a intersecção que as linhas se cruzam. Essas linhas possuem uma direção e um ponto de cruzamento, podemos associar essas formas a uma estrada, pois ela possui linhas que se cruzam no horizonte assim como as linhas já mencionadas. Novamente o horizonte é referenciado, o que complementa a ideia do nascer do sol, e agora há uma estrada direcionada para esse horizonte, ao juntarmos a qualidade da cor com as linhas, podemos associar a imagem de uma estrada em direção ao horizonte durante o nascer do sol, o começo de um novo dia.

A identidade da campanha de 2016 de Eloísio possui muita luminosidade, esse efeito visual é produzido devido a utilização do fundo branco e da sombra projetada no fundo, pelos outros elementos.

Do ponto de vista singular-indicial, o aspecto indicial é algo provocador, pois direciona para algo, e isso acontece com as linhas diagonais, no qual foram associadas a uma estrada, que indica um caminho, um rumo a seguir, que direciona o olhar e o entendimento.

Do ponto de vista convencional-simbólico, a identidade possui como legi-signos o nome dos candidatos, os cargos pretendidos e o número 13, que identifica o candidato e simboliza o partido. Mas como uma campanha eleitoral de um candidato do PT ela não possui muitos símbolos do partido, ao compararmos com a campanha de 2012, estão ausentes a 
estrela e a cor vermelha que simbolizam o partido, a cor vermelha pode se considerar que foi substituída pela cor laranja e a estrela não está presente.

Em nível interpretativo, no que se refere ao interpretante Imediato, a campanha tem como potencial mostrar de que ela se trata de uma campanha eleitoral, devido à presença de signos que indicam isso, como os cargos de prefeito e vice. E a representação do partido na campanha acontece de modo tênue, pois a cor vermelha está descaracterizada e a estrela símbolo do PT, está presente de modo que ela está muito pequena.

Quanto ao interpretante dinâmico, em nível emocional, a campanha transmite luminosidade e tranquilidade, devido à cor branca e às sombras projetadas pelo texto. Temos também a associação dos tons de laranja e das linhas que são semelhantes a uma estrada, no qual a junção desses signos produz a associação com o nascer de um novo dia, um recomeço, com uma estrada sumindo no horizonte enquanto nasce o sol de manhã.

Em nível energético, as linhas diagonais são provocativas, fazem com que o intérprete olhe o movimento dela, o caminho percorrido por elas, e buscam sua intersecção, o ponto em que se cruzam, que acontece no acento da letra "I". Outra reação que o intérprete tem à identidade visual é a de buscar signos que identifiquem o partido ao qual o candidato é filiado, e ele irá encontrar isso no número do candidato, o 13.

Em nível lógico, a metáfora (aproximar de duas coisas distintas e estabelecer uma relação de similaridade) do nascer de um novo dia, que é produzida pela associação que se faz com os tons de laranja e as linhas que formam um caminho, produzem um significado para a campanha, Eloísio foi eleito prefeito em 2012, em 2016 ele buscava se reeleger, continuar como prefeito, e ao ter noção disso a metáfora produz como significado a busca pela continuidade do trabalho em um novo mandato, a continuidade buscada é representada pela estrada e o novo mandato é representado pela associação que se faz dos tons de laranja com um novo dia. Temos também a desvinculação do partido com o candidato, pois não é utilizado nenhum símbolo do PT na identidade visual.

\section{Estratégias semiótico-comunicacionais}


Por meio das análises semióticas empreendidas, foi possível evidenciar a produção de sentido de cada identidade visual. E, ao compararmos as campanhas dos candidatos das mesmas cidades no ano de 2012 e 2016, identificaram-se as estratégias utilizadas.

\subsection{Análise comparativa das campanhas da cidade de São Paulo - estratégia: humanização}

A análise comparativa das campanhas de São Paulo, que se refere à mudança da campanha de 2012 para a campanha de 2016 de Fernando Haddad, a estratégia analisada foi nomeada de "Humanização".

A campanha de 2012 de Haddad utiliza signos muito contrastantes, as cores vermelha e preta, muito saturadas, que juntas produzem a associação com impacto, conflito, combate, temor, a campanha do candidato é criada para enfrentar as outras como se fosse em um combate.

Outro aspecto de destaque é a tipografia que se enquadra no estilo de serifa grossa, segundo Williams (2013, p.156) essa classe surgiu com a revolução industrial e a publicidade, suas linhas retas transmitem a sensação de solidez e força, todos os seus traços são grossos e com linhas perfeitamente retas e as serifas são horizontais, essas características fazem com que a tipografia não pareça ter sido produzida manualmente, e sim de modo mecânico, de modo industrial, por uma máquina.

Na campanha de 2016 observamos signos totalmente diferentes. As cores são menos conflitantes, contrastantes e saturadas. E a tipografia de mais destaque, no nome Haddad, faz parte da categoria manuscrita, que simula a ação de uma pessoa em pincelar o texto, e não mais algo industrial como na campanha anterior, aspectos qualitativos esses que corroboram a estratégia de humanizar a campanha.

Outro ponto, de valor simbólico e não qualitativo, é a utilização do símbolo da diferença na letra $\mathrm{H}$ de Haddad. Isso produz duas interpretações: de que o candidato é diferente dos outros, que no contexto de 2016, muitos estão envolvidos com corrupção, e também de que ele se preocupa em olhar para as diferenças, a diversidade. Tudo isso contribui para a construção de valores para o ser humano, a pessoa Haddad. E assim se justifica a nome dado a estratégia utilizada. 


\subsection{Análise comparativa das campanhas da cidade de Belo Horizonte -} estratégia: alegria visual

A análise comparativa das campanhas de Belo Horizonte diz respeito à mudança da campanha de 2012 de Patrus Ananias, para a campanha de 2016 de Reginaldo Lopes, a estratégia analisada foi nomeada de "Alegria Visual".

A campanha de Patrus Ananias em 2012 faz muita referência ao seu partido político o PT, no qual os signos do partido têm mais destaque que o próprio candidato. É utilizado de modo gritante as estrelas e a cor vermelha símbolos do partido, e até a sigla do partido (PT). As cores utilizadas são basicamente a cor vermelha, branca e tons de cinza.

A mudança na campanha de 2016 é muito evidente, devido à aplicação de várias cores na identidade visual, como a cor azul, amarela, vermelha, rosa, verde, todas com algumas variações tonais. Além disso, se tem a utilização de formas circulares, que produzem a sensação de movimento e animação, devido à irregularidade de sua forma. Esses aspectos conjuntamente produzem um valor contemplativo, alegre da identidade, algo que não é muito associado a campanhas políticas.

Ao realizar a comparação entre as campanhas a estratégia foi nomeada de "Alegria Visual", pois o modo de desvincular o candidato ao partido é a não utilização de signos do partido, e aplicação de signos que produzem alegria, animação, valor contemplativo a campanha.

\subsection{Análise comparativa das campanhas da cidade de Poços de Caldas -} estratégia: metáfora do alvorecer

A análise comparativa das campanhas de Poços de Caldas, refere-se a mudança da campanha de 2012 para a de 2016 de Eloísio Lourenço, a estratégia analisada foi nomeada de "Metáfora do Alvorecer".

Como foi analisada, a campanha de 2012 de Eloísio Lourenço faz vinculação com o partido por meio da cor vermelha e da estrela, mas também busca agregar ao candidato valores de importância social, como a utilização do pronome de tratamento "Dr.". A 
identidade é muito escura, utiliza o fundo na cor preta, e as cores branca e vermelha em destaque nos outros elementos.

Na campanha de 2016 a luminosidade é algo muito aparente devido à utilização da cor branca como o fundo, e do efeito de projeção de sombra dos textos sobre o fundo. Outro ponto que envolve luz é a utilização da cor laranja em alguns elementos, o modo como a cor é aplicada, com variações do escuro para o claro, se assemelham a experiência de contemplar o nascer do sol no horizonte, o nascer de um novo dia, no qual encontra-se no céu a mesma paleta de cores. Na primeira letra "O" do nome Eloísio temos algumas linhas que criam uma forma que se assemelha a uma estrada, um caminho, algo que tem continuidade.

O nascer do sol e a continuidade, ambos produzidos pelas qualidades, criam o entendimento de que o candidato que busca a reeleição busca um novo mandato, busca a continuidade no cargo. E, assim, a estratégia foi nomeada de "Metáfora do Alvorecer" (começo de um novo dia), pois se deixa de utilizar signos do partido, e se busca focar, produzir o entendimento de que ele busca continuar no mandato, através de uma metáfora, a aproximação de coisas distintas, por meio da criação de um significado semelhante, no caso as cores e o nascer do dia, o novo mandato, e assim se efetiva a metáfora do alvorecer.

\section{Considerações finais}

Por meio da análise semiótica das campanhas eleitorais, foi possível identificar as estratégias utilizadas, e descrever o que elas transmitem, os sentidos que elas produzem. Assim, fica claro que no ano de 2012, as campanhas faziam referência ao partido de modo evidente, com a constante utilização de símbolos do partido que, em alguns casos, como a campanha de Patrus, possui mais destaque do que o próprio candidato.

No ano de 2016, foi possível observar a busca por uma ocultação do partido nas campanhas, estratégia utilizada para desvincular o candidato do seu partido, estratégia que se justifica devido ao contexto conturbado na política brasileira em 2016, principalmente o cenário político do PT.

Ao compararmos as campanhas das mesmas cidades, mantêm-se os dois candidatos em duas delas (Haddad, em 2012 e 2016, em São Paulo; Eloísio Lourenço, em 2012 e 2016, em Poços de Caldas) e dois candidatos distintos em uma delas (Patrus Ananias, em 2012, e 
Reginaldo Lopes, em 2016, em Belo Horizonte). Assim, embora se mantenha o contexto geográfico, o que muda é o contexto político que acaba por afetar os valores que se relacionam aos Partido dos Trabalhadores. Desse modo, podemos evidenciar a importância do contexto na comunicação visual de cada campanha, e demonstrar como se constituiu cada estratégia de desvinculação da imagem do PT em relação à imagem de cada candidato.

\section{Referências}

ALMEIDA, Antonio Jorge Fonseca Sanches de. Evolução do comportamento político durante a atual crise no Brasil. Revista COMPOLÍTICA, 2017.

DONDIS, Donis. Sintaxe da linguagem visual. São Paulo: Martins Fontes, 2007.

GUAZINA, Liziane Soares; PRIOR, Helder; ARAÚJO, Bruno. Enquadramentos de uma crise: o impeachment de Dilma Rousseff em editoriais nacionais e internacionais. Revista COMPÓS, 2017.

PEREZ, Clotilde. Signos da Marca: Expressividade e Sensorialidade. São Paulo: Thomson, 2004.

RIZOTTO, Carla Candida; PRUDENCIO, Kelly; SAMPAIO, Rafael Cardoso. Tudo normal: a pauta antipolítica no enquadramento multimodal da cobertura do impeachment de Dilma Rousseff. Revista COMPÓS, 2017.

SANTAELLA, Lucia. O que é semiótica. São Paulo: Brasiliense, 1998.

SANTAELLA, Lucia. Semiótica aplicada. Cengage Learning Editores, 2002.

WILLIAMS, Robin. Design para quem não é designer. São Paulo: Callis, 2013. 